\title{
Risk Factors for Pancreatitis and Cholecystitis after Endoscopic Biliary Stenting in Patients with Malignant Extrahepatic Bile Duct Obstruction
}

\author{
Ga Hee Kim¹, Si Kyong Ryo0', Jae Keun Park², Joo Kyung Park², Kwang Hyuck Lee², Kyu Taek Lee² and Jong Kyun Lee² \\ Department of ${ }^{1}$ Medicine, ${ }^{2}$ Gastroenterology, Samsung Medical Center, Sungkyunkwan University School of Medicine, Seoul, Korea
}

Background/Aims: For the treatment of malignant biliary obstruction, endoscopic retrograde biliary drainage (ERBD) has been widely accepted as a standard procedure. However, post-ERBD complications can affect the lives of patients. The purpose of this study was to identify the predictive factors for these complications, including the patient's status, cancer status, and stent type.

Methods: This was a retrospective analysis conducted in a single tertiary hospital from January 2007 to July 2017. The following variables were evaluated: sex, age, body mass index, cancer type, history of pancreatitis, gallbladder stone, previous biliary stenting, precut papillotomy, stent type, contrast injection into the pancreatic duct or gallbladder, cystic duct invasion by the tumor, and occlusion of the cystic duct orifice by a metal stent.

Results: Multivariate analysis showed that contrast injection into the pancreatic duct was a risk factor for pancreatitis. Patients with a history of bile drainage showed a lower risk of pancreatitis. For cholecystitis, the analysis revealed contrast injection into the gallbladder and cystic duct invasion by the tumor as important predictive factors. Metal stents showed a greater risk of post-procedure pancreatitis than plastic stents, but did not affect the incidence of cholecystitis.

Conclusions: Considering that contrast injection is the most important factor for both complications, a careful approach by the physician is essential in preventing the occurrence of any complications. Further, choosing the type of stent is an important factor for patients at a risk of post-procedure pancreatitis. Clin Endosc 2019;52:598-605

Key Words: Cholecystitis; Endoscopic retrograde biliary drainage; Pancreatitis; Type of stent

\section{INTRODUCTION}

Patients with unresectable malignant bile duct obstruction require palliative biliary drainage. Endoscopic retrograde biliary drainage (ERBD) has become the treatment of choice for the palliation of biliary obstruction. ${ }^{1,2}$ The successful drainage rate of ERBD is $>70 \%$. The successful management of obstruc-

Received: October 11, 2018 Revised: February 7, 2019

Accepted: February 8, 2019

Correspondence: Jong Kyun Lee

Department of Medicine, Samsung Medical Center, Sungkyunkwan University School of Medicine, 81 Irwon-ro, Gangnam-gu, Seoul 06351, Korea

Tel: +82-2-3410-3409, Fax: +82-2-3410-6983, E-mail: jongk.lee@samsung.com ORCID: https://orcid.org/0000-0002-1298-0494

cc This is an Open Access article distributed under the terms of the Creative Commons Attribution Non-Commercial License (http://creativecommons.org/ licenses/by-nc/3.0) which permits unrestricted non-commercial use, distribution, and reproduction in any medium, provided the original work is properly cited. tive jaundice could increase life expectancy and decrease mortality; however, the procedure itself could be fatal to patients. Further, complications after stent placement may decrease the patient's quality of life or result in severe disorders. Pancreatitis and cholecystitis are well-known complications of stent insertion that may lead to fatal consequences. Several studies have analyzed the risk factors for pancreatitis and cholecystitis after stent insertion. ${ }^{3,4}$ Physicians are required to obtain information about each patient's risk status before performing the procedure, so that they are prepared for future treatment in the case of the development of complications.

During the ERBD procedure, physicians should consider a few aspects including stent type, guidewire approach, and the need for endoscopic sphincterectomy. While selecting the type of stent, physicians should consider many factors such as life expectancy and obstruction degree, risk of migration, and 
risk of post-procedure complication. Patients with $<4$ months of life expectancy are treated with plastic stents; however, plastic tube stents often become occluded by sludge. ${ }^{5}$ Self-expandable metallic stents (SEMS) were introduced by the end of the 1980s to overcome the disadvantages of plastic stents. Then, in the 1990s, covered SEMS (CSEMS) were developed so as to prevent tumor in-growth in SEMS. ${ }^{6,7}$ Various studies have been conducted with a focus on comparing the advantages, disadvantages, and complications associated with the procedures utilizing plastic stents, CSEMS, and uncovered SEMS (USEMS). A few meta-analyses have revealed no differences in the rates of pancreatitis and cholecystitis between CSEMS and USEMS. ${ }^{89}$ However, the previous papers also had their own limitations, and as patients show increasingly longer survival rates, additional studies need to be done. Recently, there have been reports showing that CSEMS is associated with a higher rate of cholecystitis than USEMS, ${ }^{10}$ and that SEMS with a high axial force are strongly associated with an increased incidence of pancreatitis. ${ }^{11}$ The miscellaneous results indicate the scope for further research in the field of risk factors for post-procedure complications.

The purpose of this study was to identify the predictive factors for complications after biliary stent placement by considering many aspects, including the patient's status, cancer status, and stent type; in particular, an attempt was made to consider as many variables as possible along with the analysis of all 3 stent types.

\section{MATERIALS AND METHODS}

\section{Study design and statistical analysis}

This study was a retrospective analysis using a registry of cancer patients with unresectable extrahepatic malignant bile duct obstruction who underwent ERBD and stenting from January 2007 to July $2017(n=1,080)$ at a tertiary referral center. We excluded participants for the following reasons: follow-up loss for $>3$ months, previous cholecystectomy, development of other febrile complications after the procedure during the follow-up period, and missing data. Ultimately, 375 eligible participants were included in this study. Typically, 248 patients were included in the no acute complication group, 97 patients were included in the pancreatitis group, and 30 patients were included in the cholecystitis group (Fig. 1). Subsequently, individual characteristics were analyzed and a risk factor analysis was conducted. This study was approved by the Institutional Review Board of the Samsung Medical Center, and the requirement for informed consent was waived because only de-identified data were employed. We used the chisquare test, Kruskal-Wallis rank sum test, and Fisher's exact test for comparative analysis of categorical variables. A value of $p<0.05$ was considered to be statistically significant. Univariate and multivariate logistic regression analyses were used to identify the risk factors for post-procedure pancreatitis and cholecystitis.

\section{Endoscopic procedure}

Plastic stents, CSEMS, and USEMS were placed using endoscopic retrograde cholangiopancreatography (ERCP). The stent type or procedure progression was determined by each physician based on interactions with the patient, and all of the physicians were experts in performing ERCP procedures. The papilla was managed with sphincterectomy or pre-cut papillotomy, including infundibulotomy and transpancreatic septotomy. However, a few patients did not undergo sphincterotomy because of a bleeding tendency or a previous sphincterectomy. During the analysis of the type of stents, partially covered metal stents were included in the covered metal stent group in this study. At our hospital, we did not perform prophylactic pancreatic duct stenting.

\section{Clinical outcomes}

The primary outcome of this study was the incidence of cholecystitis and pancreatitis after ERBD. Secondarily, we

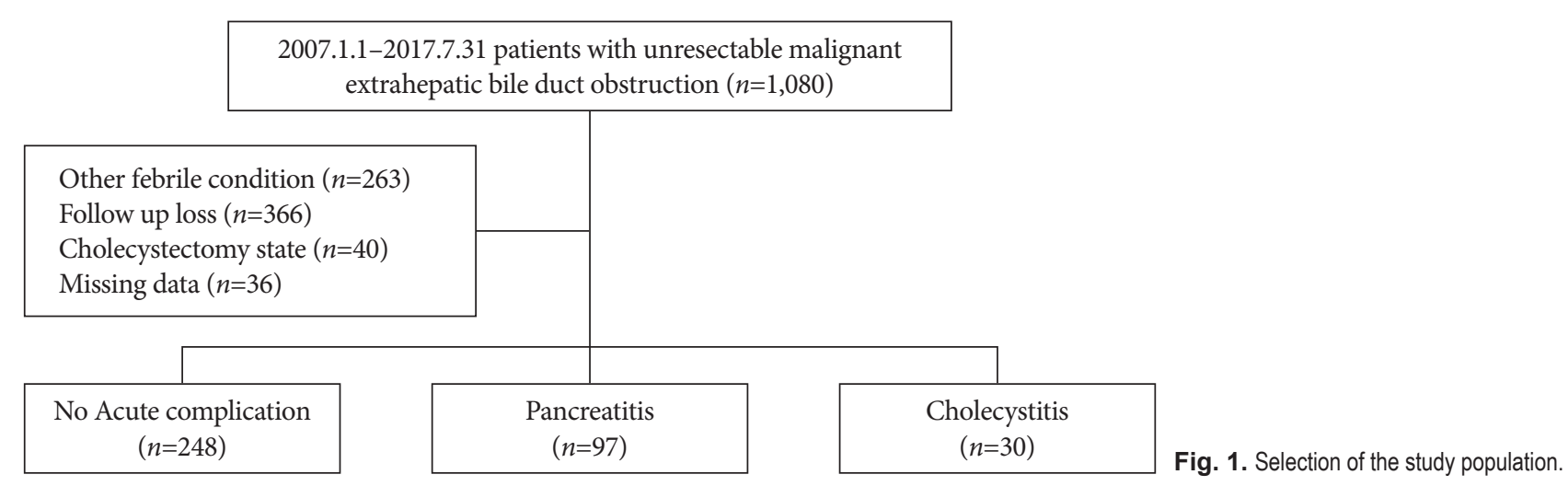


evaluated various parameters to identify the predictive factors for pancreatitis and cholecystitis. The following variables were evaluated during pancreatitis analysis: (1) sex; (2) age; (3) body mass index (BMI); (4) cancer type (pancreas cancer or non-pancreas cancer); (5) pancreatitis history; (6) previous biliary stenting including ERBD, percutaneous transhepatic biliary drainage (PTBD), and endoscopic nasobiliary drainage (ENBD); (7) pre-cut sphincterotomy; (8) stent type (plastic, covered metal, or uncovered metal); and (9) contrast injection into the pancreatic duct. The following variables were evaluated during cholecystitis analysis: (1) sex; (2) age; (3) BMI; (4) cancer type (gallbladder cancer or non-gallbladder cancer); (5) history of gallbladder stone; (6) previous biliary stenting including ERBD, PTBD, and ENBD; (7) pre-cut sphincterotomy; (8) stent type (plastic, covered metal, or uncovered metal); (9) contrast injection into the gallbladder; (10) cystic duct invasion by the tumor; and (11) occlusion of the cystic duct orifice by a metal stent.

\section{Definitions of outcomes}

\section{Pancreatitis}

The diagnosis of pancreatitis was based on the occurrence of abdominal pain after the procedure and elevation in serum amylase or lipase levels 3 times greater than the upper limit of normal.

To depict the association of pancreatitis with the procedure, the occurrence of pancreatitis was defined as the presence of symptoms within 3 days after the procedure. The grading of severity was as follows: mild, requiring admission for $\leq 3$ days due to pancreatitis; moderate, requiring admission for 4-10 days due to pancreatitis; and severe, requiring $>10$ days of hospitalization, intensive care, or surgical intervention due to pancreatitis.

\section{Cholecystitis}

The diagnosis of cholecystitis was based on the occurrence of typical abdominal pain in the right upper quadrant or epigastric area, and computed tomography or sonographic findings of cholecystitis within 3 months after stent insertion. To describe the relationship with the procedure, the occurrence of cholecystitis was defined as the presence of symptoms within 3 months after the procedure. The grading of severity was as follows: mild, requiring only antibiotics and drainage procedure due to cholecystitis; severe, requiring intensive care or requiring surgical intervention.

\section{RESULTS}

\section{Patient characteristics}

The patients' baseline characteristics are listed in Table 1; there were no prominent differences in sex, age, BMI, pancreatitis history, gallbladder stone, or stent type. However, with respect to cancer type, heterogeneity was observed in the 3 groups ( $p=0.029$ ). Pancreatic cancer accounted for $>40 \%$ in the no immediate complication group and pancreatitis group; however, in the cholecystitis group, cholangiocarcinoma accounted for only $50 \%$. For the purpose of analysis and to overcome the issue of heterogeneity, pancreatic cancer versus non-pancreatic cancer was analyzed in terms of pancreatitis, and gallbladder cancer versus non-gallbladder cancer was analyzed in terms of cholecystitis.

The onset of pancreatitis was within $24 \mathrm{~h}$ in all cases. Of the patients with pancreatitis, 61 (62.6\%) were cured by fasting, whereas $36(37.1 \%)$ were treated by fasting and with medications such as nafamostat, gabexate, or ulinastatin. The severity of pancreatitis was mild in 86 patients and moderate in 11 patients. None of the patients had severe pancreatitis. The onset of cholecystitis was within 3 months in all cases. In the patients with cholecystitis, $9(30 \%)$ were treated by fasting and antibiotics, $2(6.7 \%)$ underwent ERBD for the treatment of obstructive cholecystitis, and 19 (53.3\%) were treated by percutaneous gallbladder drainage.

\section{Risk factor analysis for post-ERBD pancreatitis}

Table 2 shows the univariate and multivariate analyses of risk factors for pancreatitis. Univariate analysis revealed that female sex, increased BMI, and contrast injection into the pancreas were significant predictive factors for pancreatitis. Further, the incidence of previous biliary stenting including ERBD and PTBD was lower in patients with pancreatitis than in patients with no complication $(p<0.0001)$. After multivariate analysis, a positive pancreatogram, representing contrast injection into the pancreatic duct, was identified as the only significant risk factor (odds ratio [OR], 6.717; 95\% confidence interval [CI], 3.627-12.439).

Because a positive pancreatogram was the largest confounder, subgroup analysis was performed in the case of patients without contrast injection into the pancreatic duct. The results of the subgroup analysis are shown in Table 3. Biliary drainage history was identified to have a decreased risk of pancreatitis (hazard ratio [HR], 0.262; 95\% CI, 0.121-0.571). In addition, in terms of the stent type, there was some difference when comparing the 3 groups $(p=0.02$ ). Therefore, additional analysis was conducted to compare different types of models: model 1, plastic versus uncovered, plastic versus covered; model 2, plastic versus metal; and model 3, USEMS versus CSEMS. 
Table 1. Patients' Baseline Characteristics

\begin{tabular}{|c|c|c|c|c|}
\hline & No immediate complication $(n=248)$ & Pancreatitis $(n=97)$ & Cholecystitis $(n=30)$ & $p$-value \\
\hline \multicolumn{5}{|l|}{$\operatorname{Sex}(\%)$} \\
\hline Male & $153(61.7)$ & $47(48.5)$ & $16(53.3)$ & 0.073 \\
\hline Female & $95(38.3)$ & $50(51.5)$ & $14(46.7)$ & \\
\hline Age (yr), mean (SD) & $62.54(12.01)$ & $64.60(12.62)$ & $66.70(10.90)$ & 0.113 \\
\hline BMI, mean (SD) & $22.30(2.81)$ & $23.13(3.17)$ & $22.89(3.46)$ & 0.055 \\
\hline Pancreatitis history (\%) & $16(6.5)$ & $6(6.2)$ & $6(20.0)$ & $0.044^{\mathrm{a})}$ \\
\hline GB stone $(\%)$ & $22(8.9)$ & $9(9.3)$ & $6(20.0)$ & 0.184 \\
\hline Stent type (\%) & & & & 0.235 \\
\hline Plastic & $100(40.3)$ & $27(27.8)$ & $13(43.3)$ & \\
\hline USEMS & $99(39.9)$ & $45(46.4)$ & $12(40.0)$ & \\
\hline CSEMS & $49(19.8)$ & $25(25.8)$ & $5(16.7)$ & \\
\hline Cancer type (\%) & & & & $0.029^{\mathrm{a})}$ \\
\hline GB cancer & $27(10.9)$ & $15(15.5)$ & $3(10.0)$ & \\
\hline Pancreas cancer & $105(42.3)$ & $41(42.3)$ & $7(23.3)$ & \\
\hline Cholangiocarcinoma & $44(17.7)$ & $19(19.6)$ & $15(50.0)$ & \\
\hline Liver cancer & $37(14.9)$ & $9(9.3)$ & $2(6.7)$ & \\
\hline Duodenal cancer & $1(0.4)$ & $0(0.0)$ & $0(0.0)$ & \\
\hline AoV cancer & $8(3.2)$ & $1(1.0)$ & $0(0.0)$ & \\
\hline Other metastatic cancer & $26(10.5)$ & $12(12.4)$ & $3(10.0)$ & \\
\hline
\end{tabular}

AoV, ampulla of Vater; BMI, body mass index; CSEMS, covered self-expandable metallic stents; GB, gallbladder; SD, standard deviation; USEMS, uncovered self-expandable metallic stents.

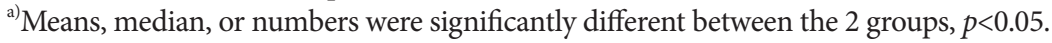

Table 2. Univariate and Multivariate Analyses of Risk Factors for Pancreatitis

\begin{tabular}{|c|c|c|c|c|}
\hline \multirow{2}{*}{ Variables } & \multirow{2}{*}{$\begin{array}{l}\text { No complication } \\
(n=248)\end{array}$} & \multirow{2}{*}{$\begin{array}{l}\text { Pancreatitis } \\
\quad(n=97)\end{array}$} & \multicolumn{2}{|r|}{$p$-value } \\
\hline & & & Univariate analysis & Multivariate analysis \\
\hline Sex, Male (\%) & $153(61.7)$ & $47(48.5)$ & $0.026^{\mathrm{a})}$ & 0.195 (OR, 1.440; 95\% CI, 0.829-2.500) \\
\hline Age (yr), mean (SD) & $62.54(12.01)$ & $64.60(12.62)$ & 0.16 & 0.160 (OR, 1.016; 95\% CI, 0.994-1.039) \\
\hline BMI $\left(\mathrm{kg} / \mathrm{m}^{2}\right)$, mean $(\mathrm{SD})$ & $22.30(2.81)$ & $23.13(3.17)$ & $0.019^{\mathrm{a})}$ & 0.056 (OR, 1.093; 95\% CI, 0.998-1.197) \\
\hline Cancer type & & & 0.636 & \\
\hline Pancreas cancer & $105(42.6)$ & $41(42.3)$ & & \\
\hline Non-pancreas cancer & $143(57.7)$ & $56(57.7)$ & & \\
\hline Pancreatitis history (\%) & $16(6.5)$ & $6(6.2)$ & 0.928 & \\
\hline $\begin{array}{l}\text { Biliary stenting history, mean } \\
\text { (SD) }\end{array}$ & $0.59(0.89)$ & $0.16(0.37)$ & $<0.0001^{\text {b) }}$ & $\begin{array}{c}<0.0001^{\mathrm{b})} \\
(\mathrm{OR}, 3.026 ; 95 \% \mathrm{CI}, 1.624-5.640)\end{array}$ \\
\hline Pre-cut $(\%)$ & $7(2.8)$ & $5(5.2)$ & 0.295 & \\
\hline \multicolumn{5}{|l|}{ Stent type (\%) } \\
\hline Plastic vs. USEMS vs. CSEMS & & & 0.0923 & 0.246 \\
\hline Plastic vs. metal & $100: 148(1: 1.48)$ & $27: 70(1: 2.59)$ & $0.032^{\mathrm{a})}$ & 0.097 (OR, 1.638; 95\% CI, 0.915-2.933) \\
\hline USEMS vs. CSEMS & 99: $49(1: 0.49)$ & $45: 25(1: 0.55)$ & 0.704 & \\
\hline Pancreatogram (\%) & $24(9.7)$ & $43(44.3)$ & $<0.0001^{\text {b) }}$ & $\begin{array}{c}<0.0001^{\mathrm{b})} \\
(\mathrm{OR}, 6.717 ; 95 \% \mathrm{CI}, 3.627-12.439)\end{array}$ \\
\hline
\end{tabular}

BMI, body mass index; CI, confidence interval; CSEMS, covered self-expandable metallic stents; OR, odds ratio; SD, standard deviation; USEMS, uncovered self-expandable metallic stents.

${ }^{a)}$ Means, medians, or numbers were significantly different between the 2 groups, $p<0.05$. ${ }^{\text {b) }}$ Means, $p<0.01$. 
Consequently, in the cases with a plastic stent, a significant reduction in the incidence of pancreatitis was observed as compared with the cases with the other 2 metal stents, and the comparative result with USEMS was more prominent (HR, 2.766; 95\% CI, 1.348-5.677; $p=0.006)$. There was no difference between USEMS and CSEMS.

\section{Risk factor analysis for post-ERBD cholecystitis}

Table 4 shows the univariate and multivariate analyses of risk factors for cholecystitis. Univariate analysis revealed that contrast injection into the gallbladder and cystic duct invasion by the tumor were the important risk factors for cholecystitis, and multivariate analysis showed similar results (OR, 3.342;

Table 3. Subgroup Analysis in Patients with No Contrast Injection into the Pancreatic Duct

\begin{tabular}{lccc}
\hline & & HR (95\% CI) & p-value \\
\hline History of biliary stent & & $0.262(0.121-0.571)$ & $0.001^{\text {b) }}$ \\
Model 1 & & $0.02^{\text {a) }}$ & $0.006^{\text {b) }}$ \\
& (Plastic vs. uncovered) & $2.89(1.365-6.118)$ & 0.058 \\
Model 2 & (Plastic vs. covered) & $2.462(0.968-6.260)$ & $0.006^{\text {b) }}$ \\
Model 3 & (Plastic vs. metal) & $2.766(1.348-5.677)$ & 0.739 \\
\hline
\end{tabular}

Model 1: adjusted for age, sex, body mass index, cancer type, history of bile drainage, pre-cut, and stent type (plastic vs. USEMS vs. CSEMS). Model 2: adjusted for age, sex, body mass index, cancer type, history of bile drainage, pre-cut, and stent type (plastic vs. metal).

Model 3: adjusted for age, sex, body mass index, cancer type, history of bile drainage, pre-cut, and stent type (USEMS vs. CSEMS).

CI, confidence interval; CSEMS, covered self-expandable metallic stents; HR, hazard ratio; USEMS, uncovered self-expandable metallic stents.

${ }^{a)}$ Means, medians, or numbers were significantly different between the 2 groups, $p<0.05$. ${ }^{\text {b) }}$ Means, $p<0.01$.

Table 4. Univariate and Multivariate Analyses of Risk Factors for Cholecystitis

\begin{tabular}{|c|c|c|c|c|}
\hline \multirow{2}{*}{ Variables } & \multirow{2}{*}{$\begin{array}{l}\text { No complication } \\
\qquad(n=248)\end{array}$} & \multirow{2}{*}{$\begin{array}{l}\text { Cholecystitis } \\
\quad(n=30)\end{array}$} & \multicolumn{2}{|r|}{$p$-value } \\
\hline & & & Univariate analysis & Multivariate analysis \\
\hline Sex, Male (\%) & $153(61.7)$ & $16(53.3)$ & 0.377 & \\
\hline Age (yr), mean (SD) & $62.54(12.01)$ & $66.70(10.90)$ & 0.073 & 0.111 (OR, 1.029; 95\% CI, 0.993-1.067) \\
\hline BMI $\left(\mathrm{kg} / \mathrm{m}^{2}\right)$, mean $(\mathrm{SD})$ & $22.30(2.81)$ & $22.89(3.46)$ & 0.289 & \\
\hline Cancer type & & & 0.754 & \\
\hline GB cancer & $27(10.9)$ & $3(9.1)$ & & \\
\hline Non-GB cancer & $221(89.1)$ & $30(90.9)$ & & \\
\hline GB stone $(\%)$ & $22(8.9)$ & $6(20.0)$ & 0.063 & 0.109 (OR, 2.297; 95\% CI, 0.832-6.340) \\
\hline $\begin{array}{l}\text { Biliary stenting history, mean } \\
\text { (SD) }\end{array}$ & $0.59(0.89)$ & $0.80(1.35)$ & 1.116 & \\
\hline Pre-cut (\%) & $7(2.8)$ & $0(0.0)$ & 0.987 & \\
\hline \multicolumn{5}{|l|}{ Stent type (\%) } \\
\hline Plastic vs. USEMS vs. CSEMS & & & 0.909 & \\
\hline Plastic vs. metal & $100: 148(1: 1.48)$ & $13: 17(1: 30)$ & 0.751 & \\
\hline USEMS vs. CSEMS & 99: $49(1: 0.49)$ & $12: 5(1: 0.41)$ & 0.759 & \\
\hline $\begin{array}{l}\text { Contrast injection to the GB } \\
(\%)\end{array}$ & $41(16.5)$ & $13(39.4)$ & $0.003^{\mathrm{a})}$ & $\begin{array}{c}0.004^{\mathrm{a})} \\
(\mathrm{OR}, 3.342 ; 95 \% \mathrm{CI}, 1.459-7.656)\end{array}$ \\
\hline $\begin{array}{l}\text { Cystic duct invasion by the } \\
\text { tumor }(\%)\end{array}$ & & & $<0.0001^{\text {b) }}$ & $\begin{array}{c}0.002^{\mathrm{a})} \\
(\mathrm{OR}, 4.076 ; 95 \% \mathrm{CI}, 1.680-9.887)\end{array}$ \\
\hline $\begin{array}{l}\text { Occlusion of the cystic duct } \\
\text { orifice by metal stent (\%) }\end{array}$ & & & 0.228 & 0.367 (OR, $1.484 ; 95 \%$ CI, 0.630-3.495) \\
\hline
\end{tabular}

BMI, body mass index; CI, confidence interval; CSEMS, covered self-expandable metallic stents; GB, gallbladder; OR, odds ratio; SD, standard deviation; USEMS, uncovered self-expandable metallic stents.

${ }^{a)}$ Means, medians, or numbers were significantly different between the 2 groups, $p<0.05$. ${ }^{\text {b) }}$ Means, $p<0.01$. 
95\% CI, 1.459-7.656; $p=0.004$ and OR, 4.076; 95\% CI, $1.680-$ 9.887; $p=0.002$, respectively). No significant difference was observed for occlusion of the cystic duct orifice by a metal stent $(p=0.367)$. With respect to gallbladder stone, the $p$-value was 0.063 in the univariate analysis, which did not indicate a significant difference. However, in the patients positive for gallbladder stone, the tendency toward a high risk of cholecystitis was apparent based on the $p$-value. Subgroup analysis was again performed in patients without contrast injection into the gallbladder, as contrast injection into the gallbladder may act as a strong confounder (Table 5). Nevertheless, we could not find any particular difference, except for a slight increase in elderly patients with an HR of 1.045 (95\% CI, 1.002-1.089).

\section{DISCUSSION}

Our study clarified some predictive factors for pancreatitis and cholecystitis in patients with unresectable cancer-related malignant bile duct obstruction. Contrast injection into the pancreatic duct was a predictive factor for pancreatitis, whereas contrast injection into the gallbladder and cystic duct invasion by the tumor were predictive factors for cholecystitis after ERBD for malignant biliary obstruction. With respect to stents, metal stents including covered and uncovered stents exhibited an increased risk of post-procedure pancreatitis than plastic stents, but demonstrated no difference in the incidence of cholecystitis.

In previous studies, the incidences of pancreatitis and cholecystitis were approximately $5 \%-10 \%{ }^{12-14}$ In this study, the incidence of post-ERCP pancreatitis (26\%) was higher than expected based on previous studies, because we routinely check the serum amylase and lipase levels on the next day of the ERCP, and values 3 times the upper limit could be diagnosed as post-ERCP pancreatitis with mild abdominal discomfort.
Further, as confirming the discharge was delayed for $>1$ day because of abdominal discomfort, we attempted to meet the diagnostic criteria.

In this study, higher BMI did not depend on predictive factors in multivariate analysis but was statistically significant in univariate analysis. Obesity promotes inflammation and inhibits autophagy, creating an environment that induces and causes the progression of pancreatitis. ${ }^{15}$ In the present study, the mean BMI of patients with pancreatitis was higher than that of patients in the no complication group by approximately $0.83 \mathrm{~kg} / \mathrm{m}^{2}$. Although the difference was not large, it is still reasonable to propose that patients with gross obesity should be managed carefully after the procedure for the possible development of pancreatitis.

Contrast injection into the pancreatic duct or gallbladder was the significant independent predictive factor for pancreatitis and cholecystitis, as well as the most important predisposing factor.

Contrast injection into the pancreatic duct has already been reported to be a risk factor for post-ERBD pancreatitis and to be possibly related to difficulty in cannulation. ${ }^{12}$ Obviously, it is important to avoid unnecessary pancreatography when performing ERCP. However, there exist limitations to the human procedure, as a few reports have proposed that the prophylactic placement of a pancreatic duct stent may decrease the risk of pancreatitis after ERBD based on its efficacy in preventing post-ERCP pancreatitis in high-risk patients. ${ }^{16,17}$ However, at our hospital, we did not perform prophylactic pancreatic duct stenting. This is because of the additional costs associated with the additional endoscopic procedures for stent removal.

Similarly, contrast injection into the gallbladder was observed as a predictive factor for cholecystitis after malignant biliary obstruction in our study, and it may possibly be related to the location of cancer, because if the cancer is in the vicinity of the cystic duct orifice, there may be retention of the

Table 5. Subgroup Analysis in Patients with No Contrast Injection to the Gallbladder

\begin{tabular}{lccc}
\hline & & HR (95\% CI) & $p$-value \\
\hline Age & & $1.045(1.002-1.089)$ & $0.04^{\mathrm{a})}$ \\
Model 1 & & 0.83 & 0.7 \\
& (Plastic vs. uncovered) & $0.812(0.282-2.339)$ & 0.558 \\
Model 2 & (Plastic vs. covered) & $0.674(0.180-2.523)$ & 0.582 \\
Model 3 & (Plastic vs. metal) & $0.762(0.291-2.000)$ & 0.923 \\
\hline
\end{tabular}

Model 1: adjusted for age, sex, body mass index, cancer type, history of bile drainage, pre-cut, and stent type (plastic vs. USEMS vs. CSEMS). Model 2: adjusted for age, sex, body mass index, cancer type, history of bile drainage, pre-cut, and stent type (plastic vs. metal). Model 3: adjusted for age, sex, body mass index, cancer type, history of bile drainage, pre-cut, and stent type (USEMS vs. CSEMS). CI, confidence interval; CSEMS, covered self-expandable metallic stents; HR, hazard ratio; USEMS, uncovered self-expandable metallic stents. ${ }^{a)}$ Means, medians, or numbers were significantly different between the 2 groups, $p<0.05$. 
contrast agent. Previous studies have suggested that the incidence of cholecystitis may be related to the location of cancer, especially across the cystic duct orifice, ${ }^{18}$ and our study can support this claim. The occlusion of the opening of the cystic duct by the tumor or stent placement causes insufficient bile drainage, which can be a predictive risk factor for cholecystitis.

Our study did not recognize the presence of gallstone as a significant risk factor for cholecystitis; however, based on the $p$-value (0.063), we were able to presume the tendency of high-risk cholecystitis in patients with gallbladder stone. Bile flow around the cholelithiasis may depend on the size, number, and location of gallstones. Therefore, theoretically, patients with gallbladder stones are at a high risk for late biliary complications after ERCP. In addition, as suggested by Tsujino et al., the long-term outcomes of complications become favorable when patients with concomitant gallbladder stones undergo cholecystectomy. ${ }^{19}$

Among the 3 types of stents, it was difficult to identify any difference in the overall analysis; however, after correcting for the presence of a pancreatogram, metal stents were found to more likely lead to post-ERBD pancreatitis than plastic stents. Axial force is the recovery force that straightens the stent after it had bended from the sides. Several studies reported that stents with a high axial force were strongly associated with a high incidence of pancreatitis, and speculated that the axial force may compress the pancreatic duct. ${ }^{11}$ Plastic stents were left in place with no changes; however, metal stents can follow the above mechanism, thus increasing the possibility of pancreatitis. There was no difference between USEMS and CSEMS in terms of pancreatitis.

Some studies have reported on the association between the SEMS type and the risk of cholecystitis. In a recent study, increased rates of cholecystitis in CSEMS compared with USEMS were demonstrated; ${ }^{10}$ this is because interruption of bile flow from the gallbladder by covered stents may affect the pathophysiology of acute cholecystitis. However, our study did not demonstrate increased rates of cholecystitis among stent groups. Further studies on the different types of stents and complications involving a larger number of patients are thus necessary.

According to the results of a recent meta-analysis, endoscopic sphincterotomy preceding biliary stenting shows a protective effect against post-ERCP pancreatitis in patients with proximal bile duct obstruction. ${ }^{20,21}$ In our study, patients with a bile drainage history also showed a lower risk of pancreatitis. This may be because the development of pancreatitis was common during cannulation, and a previous endoscopic sphincterectomy status makes cannulation easier.

This study has several limitations. First, as this was a ret- rospective study, unrecognized biases may have existed. In particular, the situation at the time of the procedure could not be confirmed accurately, and the presence of contrast is confirmed through photographs after the procedure. Second, the small number of study patients, the heterogeneity in the types of cancer, and the various stent types can lead to biased judgments. Different stents made by various manufacturers may have different axial force values. Hence, as the number of patients was small, it was difficult to interpret the results. Third, we included partially covered metallic stents in the covered metal stent group, as only a few patients had this stent type. Despite these limitations, the present study has some strengths. We included the maximum parameters of the patients and cancer characteristics by evaluating 3 different types of stents in all cases. Previous studies demonstrated a tendency toward focusing on the differences between USEMS and CSEMS (metal stents), or in terms of metal versus plastic; however, in this study, we performed analysis of all 3 types, as well as of plastic versus metal stents and USEMS versus CSEMS.

Endoscopic biliary stent placement is a well-established palliative treatment for patients with inoperable malignant obstruction. However, this procedure is associated with several complications including pancreatitis and cholecystitis, which affect the quality of life of patients. Thus, there is a need for further studies to determine the risk factors for post-procedure pancreatitis and cholecystitis. In this study, various factors were analyzed, but contrast injection into the pancreatic duct and gallbladder was the significant independent risk factor for both pancreatitis and cholecystitis. This suggests that a careful approach by the physician is essential in preventing post-procedure complications. With respect to stents, our study showed that metal stents have a higher risk than plastic stents of causing post-ERBD pancreatitis.

In conclusion, it is important for physicians to perform ERCP carefully in patients with several risk factors for complications. Further research can aid the development of various stents and procedures, which may be helpful to physicians in selecting the appropriate stent type or procedure type, or in prescribing prophylactic medications in difficult cases. This approach will help avoid severe complications in patients.

\section{Conflicts of Interest}

The authors have no financial conflicts of interest.

\section{Author Contributions}

Conceptualization: Ga Hee Kim, Si Kyong Ryoo, Jong Kyun Lee Data curation: GHK, SKR

Formal analysis: GHK, SKR

Supervision: Jae Keun Park, Joo Kyung Park, Kwang Hyuck Lee, Kyu Taek Lee, JKL 
Writing-original draft: GHK, SKR

Writing-review\&editing: JKL

\section{REFERENCES}

1. Smith AC, Dowsett JF, Russell RC, Hatfield AR, Cotton PB. Randomised trial of endoscopic stenting versus surgical bypass in malignant low bileduct obstruction. Lancet 1994;344:1655-1660.

2. ASGE Technology Assessment Committee, Pfau PR, Pleskow DK, et al. Pancreatic and biliary stents. Gastrointest Endosc 2013;77:319-327.

3. Isayama $\mathrm{H}$, Kawabe $\mathrm{T}$, Nakai $\mathrm{Y}$, et al. Cholecystitis after metallic stent placement in patients with malignant distal biliary obstruction. Clin Gastroenterol Hepatol 2006;4:1148-1153.

4. Isayama $\mathrm{H}$, Komatsu Y, Tsujino T, et al. A prospective randomised study of "covered" versus "uncovered" diamond stents for the management of distal malignant biliary obstruction. Gut 2004;53:729-734.

5. Sawas T, Al Halabi S, Parsi MA, Vargo JJ. Self-expandable metal stents versus plastic stents for malignant biliary obstruction: a meta-analysis. Gastrointest Endosc 2015;82:256-267.e7.

6. Isayama H, Nakai Y, Kawakubo K, et al. Covered metallic stenting for malignant distal biliary obstruction: clinical results according to stent type. J Hepatobiliary Pancreat Sci 2011;18:673-677.

7. Saleem A, Leggett CL, Murad MH, Baron TH. Meta-analysis of randomized trials comparing the patency of covered and uncovered self-expandable metal stents for palliation of distal malignant bile duct obstruction. Gastrointest Endosc 2011;74:321-327.e1-e3.

8. Minami Y, Kudo M. Hepatocellular carcinoma with obstructive jaundice: endoscopic and percutaneous biliary drainage. Dig Dis 2012;30:592-597.

9. Almadi MA, Barkun AN, Martel M. No benefit of covered vs uncovered self-expandable metal stents in patients with malignant distal biliary obstruction: a meta-analysis. Clin Gastroenterol Hepatol 2013;11:27-37.e1.

10. Jang S, Stevens T, Parsi M, et al. Association of covered metallic stents with cholecystitis and stent migration in malignant biliary stricture.
Gastrointest Endosc 2018;87:1061-1070.

11. Kawakubo K, Isayama H, Nakai Y, et al. Risk factors for pancreatitis following transpapillary self-expandable metal stent placement. Surg Endosc 2012;26:771-776.

12. Shimizu S, Naitoh I, Nakazawa T, et al. Predictive factors for pancreatitis and cholecystitis in endoscopic covered metal stenting for distal malignant biliary obstruction. J Gastroenterol Hepatol 2013;28:68-72.

13. Prat F, Chapat O, Ducot B, et al. A randomized trial of endoscopic drainage methods for inoperable malignant strictures of the common bile duct. Gastrointest Endosc 1998;47:1-7.

14. Kaassis M, Boyer J, Dumas R, et al. Plastic or metal stents for malignant stricture of the common bile duct? Results of a randomized prospective study. Gastrointest Endosc 2003;57:178-182.

15. Gukovsky I, Li N, Todoric J, Gukovskaya A, Karin M. Inflammation, autophagy, and obesity: common features in the pathogenesis of pancreatitis and pancreatic cancer. Gastroenterology 2013;144:1199-1209.e4.

16. Pan XP, Dang T, Meng XM, Xue KC, Chang ZH, Zhang YP. Clinical study on the prevention of post-ERCP pancreatitis by pancreatic duct stenting. Cell Biochem Biophys 2011;61:473-479.

17. Ito K, Fujita N, Kanno A, et al. Risk factors for post-ERCP pancreatitis in high risk patients who have undergone prophylactic pancreatic duct stenting: a multicenter retrospective study. Intern Med 2011;50:29272932.

18. Suk KT, Kim HS, Kim JW, et al. Risk factors for cholecystitis after metal stent placement in malignant biliary obstruction. Gastrointest Endosc 2006;64:522-529.

19. Tsujino T, Kawabe T, Isayama $\mathrm{H}$, et al. Management of late biliary complications in patients with gallbladder stones in situ after endoscopic papillary balloon dilation. Eur J Gastroenterol Hepatol 2009;21:376-380.

20. Tarnasky PR, Cunningham JT, Hawes RH, et al. Transpapillary stenting of proximal biliary strictures: does biliary sphincterotomy reduce the risk of postprocedure pancreatitis? Gastrointest Endosc 1997;45:46-51.

21. Sofi AA, Nawras A, Alaradi OH, Alastal Y, Khan MA, Lee WM. Does endoscopic sphincterotomy reduce the risk of post-endoscopic retrograde cholangiopancreatography pancreatitis after biliary stenting? A systematic review and meta-analysis. Dig Endosc 2016;28:394-404. 